\title{
Hope and patients with advanced cancer
}

Wahl L,(1) Tricou C(2), Sisoix C(3), Ruer M(2), Legenne M (4), Zerbib Y(1) , Goffette J(1) , Filbet M. (2)

1.Collège de Médecine Générale, Université de Lyon; 2. Palliative Medicine Department, CHU Lyon Sud

3.Oncology Department, CHU Lyon Sud ; 4. Palliative Medicine Department, CHU Croix-Rousse

lucile.wahl@gmail.com

\section{CONTEXT}

- Patients in palliative care units sometimes continue to hope for a cure or to express hopes that go beyond the medical prognosis.

- When confronted to such "unrealistic hopes", doctors find it difficult to reconcile their duty to inform patients while allowing them to maintain hope.

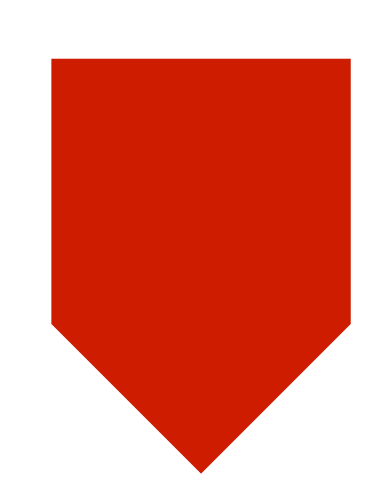

Our aim was to explore the role and meaning of hope for patients with advanced cancer, in order to find clues to solve this dilemma. semi-structured interviews data analysis used grounded theory.

The participants were adult patients from two academic medical center with an advanced cancer and followed by pallaitive care services
1 Cancer is experienced
as a global trauma

2

Yet, Hope is a vital need
It is perceived as an intrusion, responsible for

\section{3}

Patients build up hope in different ways

4

Uncertainty is a key component for hope
"Cancer eats away little by little"

"I live from day to day"

"It is what helps you keep on living"

"there are things that belong to something else" and sociological destruction.

Many patients express the need to avoid thinking about the future.

Patients describe different kinds of hope: hope for a cure, specific hopes oriented towards identified goals and "hope for life"

They believe there are forces that influence their future, beyond medical knowledge.

"It isn't that I ignore it, I know that I'm ill, but I don't make it concrete. To me, I'm not ill. That way I can go on."

When reality is too difficult to deal with, patients express the need to escape from reality, in order to keep hope.

"Who knows who will die first of you or me? Nobody knows. So that makes me cling to life. I tell myself there are possibilities... something is possible! »
Patients want their doctor to let them hope, by acknowledging the fundamental uncertainty about the evolution of cancer. physical, psychological

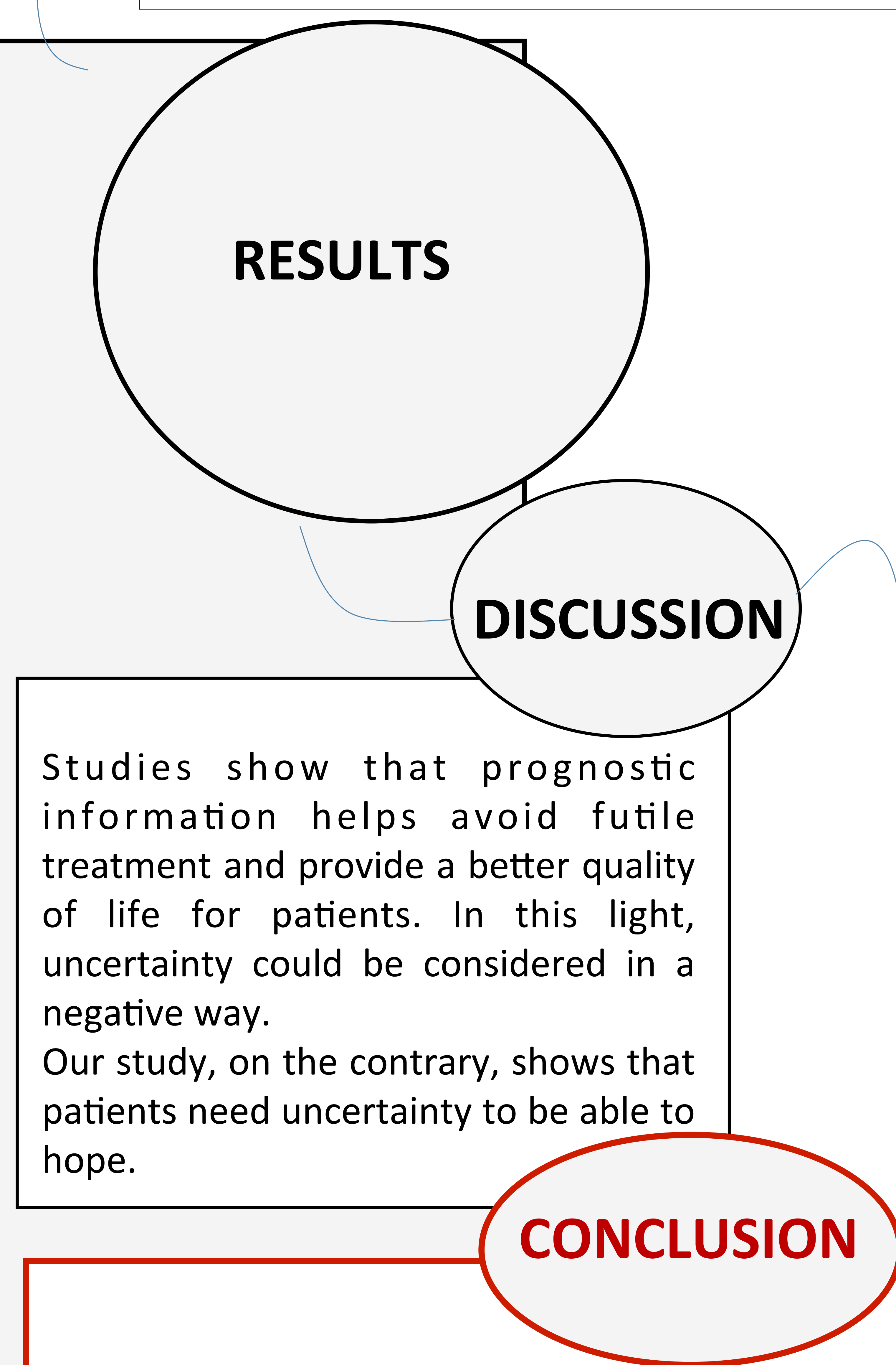

Hope is vital for patients and shouldn't be mistaken for denial.

Patients expect their doctor to give them honest information.

Medical information should take into account the uncertainty about the future, in order to allow patients to hope and give meaning to their life. 